\title{
Risk of neurodevelopmental disorders in children born from different ART treatments: a systematic review and meta- analysis
}

Tono Djuwantono ${ }^{1,2^{*}}$, Jenifer Kiem Aviani ${ }^{2}$, Wiryawan Permadi ${ }^{1}$, Tri Hanggono Achmad ${ }^{3,4}$ and Danny Halim ${ }^{4}$

\begin{abstract}
Background: Various techniques in assisted reproductive technology (ART) have been developed as solutions for specific infertility problems. It is important to gain consensual conclusions on the actual risks of neurodevelopmental disorders among children who are born from ART. This study aimed to quantify the relative risks of cerebral palsy, intellectual disability, autism spectrum disorder (ASD), and behavioral problems in children from different ART methods by using systematic review and meta-analysis. Healthcare providers could use the results of this study to suggest the suitable ART technique and plan optimum postnatal care.
\end{abstract}

Methods: Pubmed, Google Scholar, and Scopus databases were used to search for studies up to January 2020. Of the 181 screened full manuscripts, 17 studies (9.39\%) fulfilled the selection criteria. Based on the Newcastle-Ottawa scale ratings, 7 studies were excluded, resulting in 10 studies that were eventually included in the meta-analyses. Mantel-Haenszel risk ratio model was used in the meta-analysis, and the results are described using forest plot with 95\% confidence interval. Heterogeneity was assessed using the $P^{2}$ value.

Results: Pooled evaluation of 10 studies showed that the risk of cerebral palsy in children from assisted reproductive technology (ART) is higher than children from natural conceptions (risk ratio [RR] 1.82, [1.41, 2.34]; $P=0.00001)$. Risk of intellectual disability (RR 1.46, $[1.03,2.08] ; P=0.03)$ and $\operatorname{ASD}(\operatorname{RR} 1.49[1.05,2.11] ; P=0.03)$ are higher in intracytoplasmic sperm injection (ICSI) children compared to conventional in vitro fertilization (IVF) children. The differences in the risk of neurodevelopmental disorders in children born after frozen and fresh embryo transfers are not significant. Analysis on potential cofounder effects, including multiple birth, preterm birth, and low birth body weight highlight possibilities of significant correlation to the risks of neurodevelopmental disorders.

\footnotetext{
* Correspondence: tono.djuwantono@unpad.ac.id

'Department of Obstetrics and Gynecology, Faculty of Medicine, Universitas

Padjadjaran/Dr. Hasan Sadikin General Hospital, Bandung, West Java,

Indonesia

${ }^{2}$ Bandung Fertility Center, Limijati Mother and Child Hospital, Bandung, West Java, Indonesia

Full list of author information is available at the end of the article
}

C The Author(s). 2020 Open Access This article is licensed under a Creative Commons Attribution 4.0 International License, which permits use, sharing, adaptation, distribution and reproduction in any medium or format, as long as you give appropriate credit to the original author(s) and the source, provide a link to the Creative Commons licence, and indicate if changes were made. The images or other third party material in this article are included in the article's Creative Commons licence, unless indicated otherwise in a credit line to the material. If material is not included in the article's Creative Commons licence and your intended use is not permitted by statutory regulation or exceeds the permitted use, you will need to obtain permission directly from the copyright holder. To view a copy of this licence, visit http://creativecommons.org/licenses/by/4.0/. The Creative Commons Public Domain Dedication waiver (http://creativecommons.org/publicdomain/zero/1.0/) applies to the data made available in this article, unless otherwise stated in a credit line to the data. 
(Continued from previous page)

Conclusions: Pooled estimates suggest that children born after ART are at higher risk of acquiring cerebral palsy.

ICSI treatment causes higher risk of intellectual disability and ASD. These findings suggest the importance of the availability of intensive care unit at the time of delivery and long-term developmental evaluation particularly in children from ICSI.

Keywords: Neurodevelopmental disorders, Long-term outcome, Cerebral palsy, Intellectual disability, Autism spectrum disorder, Assisted reproductive treatments, In vitro fertilization, Intracytoplasmic sperm injection, Frozen embryo transfer

\section{Introduction}

The dreams of many infertile couples to have offspring(s) have been made possible by assisted reproductive technology (ART). Through its constant development, morbidity due to infertility has been massively decreased [1]. Every technique, such as intracytoplasmic sperm injection (ICSI) and frozen embryo transfer, is designed as solutions for specific problems. For example, in cases where two previous conventional in vitro fertilization (IVF) failed, or if the majority of sperms are immotile, ICSI is the technique that offers the highest possibility to acquire pregnancy(ies) [2]. Meanwhile, when couples preferred to obtain pregnancy(-ies) at later stage(s), cryopreservation enables them to freeze embryos for implantation at later times [3].

Studies on prenatal and postnatal outcomes in ART, such as the risks of multiple pregnancies and congenital malformations, have already been comprehensively reviewed and meta-analyzed on previous publications [4-10]. Conversely, lesser number of studies have focused on the neurodevelopmental aspects of children from ART. The nature of certain neurodevelopmental disorders that might not be visible until later stage in children's lives, difficulties in obtaining long-term follow-up, and the fact that many disorders can only be diagnosed and treated in a multidisciplinary fashion might be some of the reasons that caused limitation in the number of studies on neurodevelopmental outcomes in these children. Nonetheless, several studies have been published to date, and it is important to gain consensual conclusions on the actual risks of neurodevelopmental disorders among these children.

This study aims to assess the risks of neurodevelopmental abnormalities in children from ART treatments, in comparison to naturally conceived children through meta-analysis. As different ART treatments may translate into different pathophysiology, the neurodevelopmental outcomes in children from different ART techniques are also compared.

\section{Methods}

\section{Literature search and identification}

This systematic review and meta-analysis was conducted according to the Preferred Reporting Items for
Systematic Reviews and Meta-analyses (PRISMA) [11] reporting guidelines. PubMed, Scopus, and Google scholars' databases were used to collect publications up to January 16, 2020. The following search terms were applied: reproductive techniques, assisted OR assisted reproductive $\mathrm{OR}$ in vitro fertilization $\mathrm{OR}$ in vitro fertilization AND Child development OR adolescent development OR long term follow-up OR Developmental disabilities OR Developmental disability OR Language disorders OR Language disorder OR Neurodevelopment OR mental disorder OR mental disorders OR neuropsychiatry. Additional studies were identified through screening of the reference lists.

\section{Inclusion and exclusion criteria}

Studies were included if they (1) compared any neurodevelopment aspects in ART children to children from natural conceptions, and (2) described the neurodevelopment in children from common ART techniques, including conventional IVF, ICSI, cryopreserved, and fresh embryo transfers, then compared them to either children in general population or children conceived by different treatment modalities. Studies were excluded if (1) information were insufficient, particularly related to the subjects and parameters in the study, (2) not including original data, such as reviews, systematic reviews, comments, or editorial letters, (3) not including control group (e.g., case reports), or could not ascertain the used fertility treatment, and (4) not written in English.

\section{Data collection and analysis}

The title and abstract of every article were independently reviewed by 3 authors (TD, JKA, DH). If the abstract met the inclusion criteria, the full-text article was thoroughly reviewed. Reference lists on the identified publications were screened for previously unidentified but relevant studies. The following information were retrieved: author, country, publication year, number of patients, criteria of neurodevelopmental disorders, and the patients' neurodevelopmental outcomes. The quality of methodology was assessed using the risk of bias criteria that were specified in Newcastle-Ottawa Scale (NOS) 
[12]. Based on the final ratings, high-quality studies (NOS score $>7$ ) were included in the meta-analyses.

\section{Statistical analysis}

Meta-analysis was performed using Mantel-Haenszel risk ratio (RR) with 95\% confidence interval for dichotomous data. Meta-analysis was performed on subgroup analysis based on the types of the acquired neurodevelopmental disorders, including cerebral palsy, intellectual disability, autism spectrum disorder, and behavioral problems. To describe the overall risk of neurodevelopmental disorders, a meta-analysis of the overall data was also conducted. The RevMan version 5.3 software (Cochrane Collaboration) was used for these purposes. Inconsistency index $\left(I^{2}\right)$ test, which ranges from 0 to $100 \%$, was calculated to evaluate heterogeneity across studies. Values above $50 \%$ or $p$ value $<0.10$ indicate a significant heterogeneity. Regression-based Egger's test was used to evaluate small study effect and the risk of publication bias. $p$ values less than 0.05 were considered as significant bias. Cochrane Risk of Bias Assessment tool (Cochrane Collaboration) was used to assess the risk of bias. Certainty of the evidence quality was evaluated by using the Guideline Development Tool by GRADEpro.

\section{Results}

The literature searches identified 1511 studies. Additionally, 32 studies were identified through reference screening (Fig. 1). In total, 181 full-text articles were reviewed, and only 17 articles fulfilled the inclusion criteria. Based on the Newcastle-Ottawa scale ratings, 7 studies [13-19] were excluded. Thus, 10 studies [20-29] were included in the meta-analyses, including 8 cohorts and 2 casecontrol studies. Newcastle-Ottawa Scale results for the cohort studies are described on Supplemental Table 1, while descriptions of the case-control studies are reviewed on Supplemental Table 2. Characteristics of the included studies are presented on Supplemental Table 3.

\section{ART vs natural conception (non-art) (10 studies) Risk of cerebral palsy}

Prevalence of cerebral palsy was reported in 5 studies $[21,22,26,27,29]$. ART was associated with higher risk of cerebral palsy (RR $1.82[1.41,2.34], z=4.61, p<$ 0.00001; $I^{2}=19 \%, p=0.29$ ) (Fig. 2a), with an absolute risk of 7 per 1000 births at ART group and 4 per 1000 births at baseline population (Supplemental Table 5). No risk of publication bias (Egger's $p=0.501$ ) and no smallstudy bias (Habord's $p=0.962$, Peter's $p=0.991$ ) were acknowledged (Supplemental Table 4).

\section{Risk of intellectual disability}

Risk of intellectual disability (new terminology for mental retardation in DSM-5 and ICD-11) [30] was reported in 5 studies [20,21, 26, 28, 29]. Risk of intellectual disability in children born after ART treatments was not different from the risk in children from natural conceptions (RR 1.01 [0.85,1.21]; $z=0.14, p=0.89 ; I^{2}=49 \%, p$ $=0.10$ ) (Fig. 2b), with the same absolute risk of 3 per 1000 births (Supplemental Table 5). Risk of publication bias (Egger's $p=0.754$ ) and small-study bias (Habord's $p$ $=0.872$, Peter's $p=0.963$ ) were undetected (Supplemental Table 4).

\section{Risk of autism spectrum disorder}

Six studies reported the risk of ASD [20, 21, 23-25, 28]. One study [24] was excluded as it did not include children from natural conceptions as control. The risk of acquiring ASD in ART children is insignificantly different with its risk in naturally conceived children (RR 0.98 [0.86, 1.11], $z=0.33, p=0.74 ; I^{2}=0 \%, p=0.72$ ) (Fig. 2c), with identical absolute risk at 6 per 1000 births (Supplemental Table 5). Risk of publication bias (Egger's $p=$ 0.290 ) and small-study bias (Habord's $p=0.836$, Peter's $p=0.506$ ) were unidentified (Supplemental Table 4).

\section{Behavioral problems}

Risk of behavioral problems was reported in 2 studies $[20,29]$, and the results showed no differences in this risk between ART and naturally conceived group (RR 1.04 $[0.89,1.21], z=0.48, p=0.63 ; I^{2}=11 \%, p=0.29$ ) (Fig. 2d). The absolute risk is 19 children per 1000 births at ART group and 18 per 1000 births at naturally conceived group (Supplemental Table 5). Risk of bias and small-study effects could not be estimated due to limited studies $(n=2)$.

Meta-analysis on the overall data showed that ART children have a higher overall risk of neurodevelopmental disorders (RR 1.05 [0.97, 1.14], $z=1.29, p=0.20 ; I^{2}=$ $54 \%, p=0.005)$. Heterogeneity was identified for the overall studies, and this might be due to cofounder effects. The overall studies showed no risk of publication bias (Egger's $p=0.501$ ) and no small-study bias (Habord's $p=0.962$, Peter's $p=0.991$ ) (Supplemental Table 4). The absolute risk effect showed no increase in number of children born with neurodevelopmental disorders with a baseline population risk of 3 per 1000 births (Supplemental Table 5).

\section{ICSI vs conventional IVF (5 studies)}

Risk of cerebral palsy

Prevalence of cerebral palsy in children from ICSI and conventional IVF was reported in 2 studies [22, 26]. ICSI procedure causes no increase in the prevalence of cerebral palsy compared to conventional IVF (RR 0.83 [0.49, 


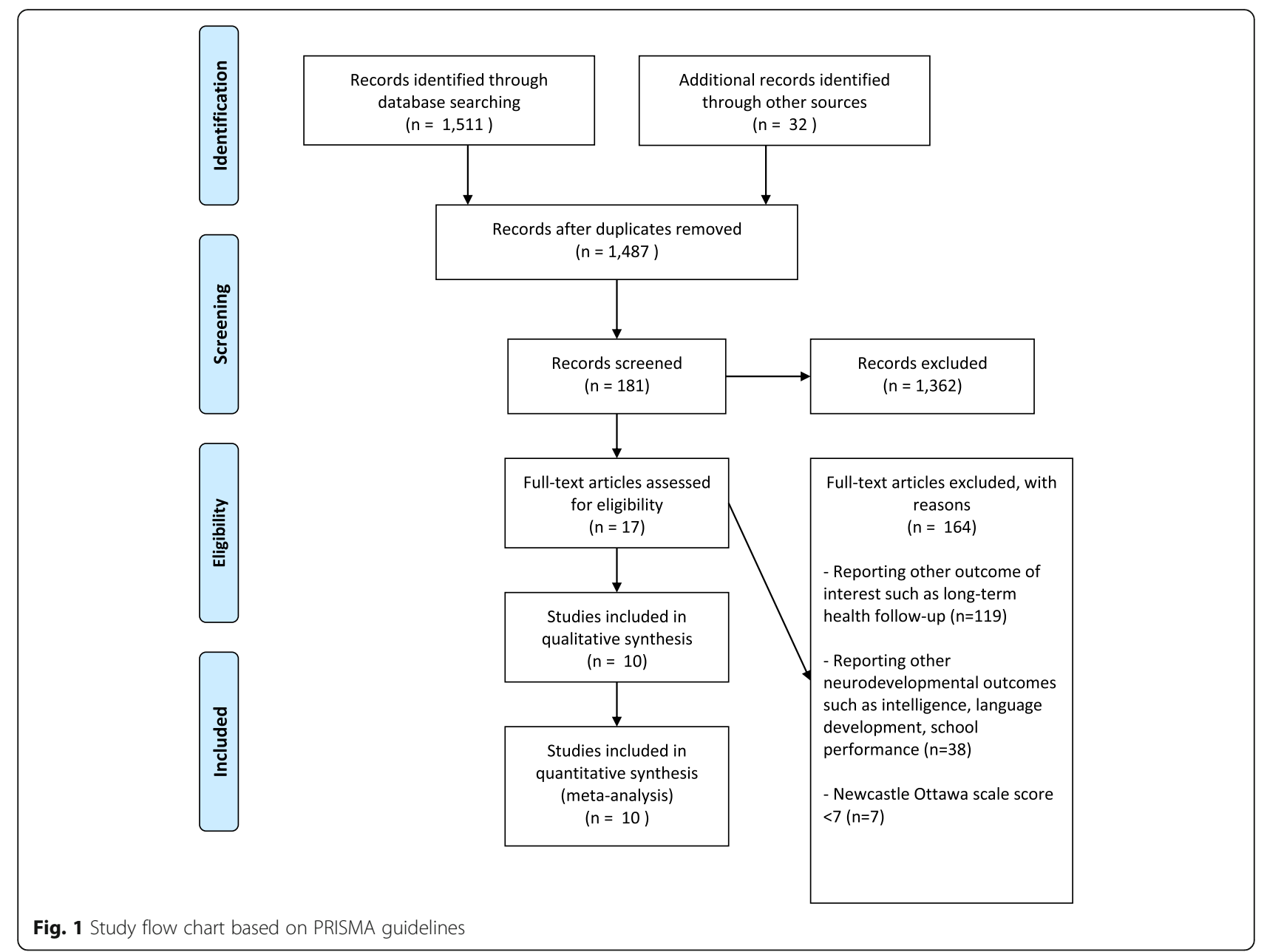

1.42], $z=0.67, p=0.50 ; I^{2}=0 \%, p=0.72$ ) (Fig. 3a), with an absolute risk 1 fewer children per 1000 birth at ICSI group, while IVF population risk is 4 per 1000 births (Supplemental Table 6). The risk of bias statistic and small-study effects could not be estimated (Supplemental Table 4).

\section{Risk of intellectual disability}

Prevalence of intellectual disability was reported in 3 studies [21, 26, 28]. An increased risk of intellectual disability was identified in the ICSI group compared to conventional IVF (RR 1.46 [1.03, 2.08]; $z=2.13, p=$ $0.03 ; I^{2}=46 \%, p=0.16$ ) (Fig. $3 \mathrm{~b}$ ), with absolute risk at ICSI group is 5 per 1000 births, while in IVF group is 3 per 1000 births (Supplemental Table 6). No risk of publication bias (Egger's $p=0.487$ ) and small-study bias (Habord's $p=0.786$, Peter's $p=0.311$ ) were detected (Supplemental Table 4).

\section{Risk of autism spectrum disorder}

The number of children diagnosed with ASD was reported in 2 studies $[24,28]$. There is an increased risk of
ASD in children born after ICSI procedure compared to conventional IVF (RR 1.49 [1.05, 2.11], $z=2.23, p=$ $0.03 ; I^{2}=0 \%, p=0.39$ ) (Fig. 3c), with an absolute risk effect of 1 more children per 1000 births compared to IVF population risk of 2 per 1000 births (Supplemental Table 6). The risk of bias statistic and small-study effects could not be calculated (Supplemental Table 4).

The overall evaluation showed higher prevalence of neurodevelopmental disorders in children from ICSI compared to children from conventional IVF (RR 1.49 $[1.05,2.11], z=2.23, p=0.03 ; I^{2}=0 \%, p=0.39$ ).

\section{Frozen vs fresh embryo transfer (6 studies)}

Risk of cerebral palsy

Prevalence of cerebral palsy was reported in 3 studies [22, 26, 27]. Risk of cerebral palsy in children from frozen embryo transfer was similar to fresh embryo transfer (RR $0.97[0.55,1.73], z=0.09, p=0.93 ; I^{2}=13 \%, p=$ 0.32 (Fig. 4a), with an absolute risk of 64 children in frozen group and 66 children in fresh group per 1000 births or 2 less children at risk compared to fresh group (Supplemental Table 7). The high number of children at risk 


\section{A. Cerebral Palsy}

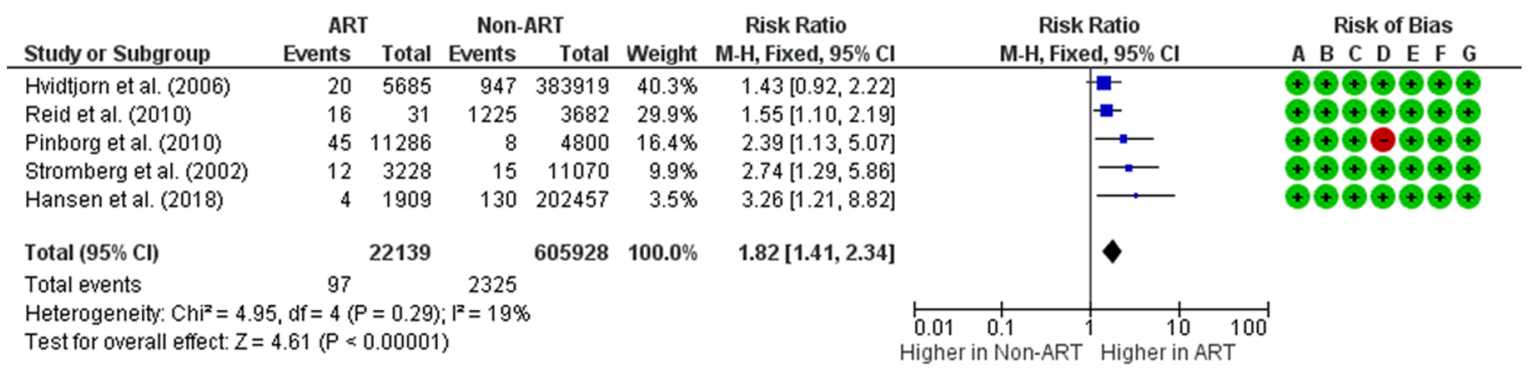

\section{B. Intellectual Disability}

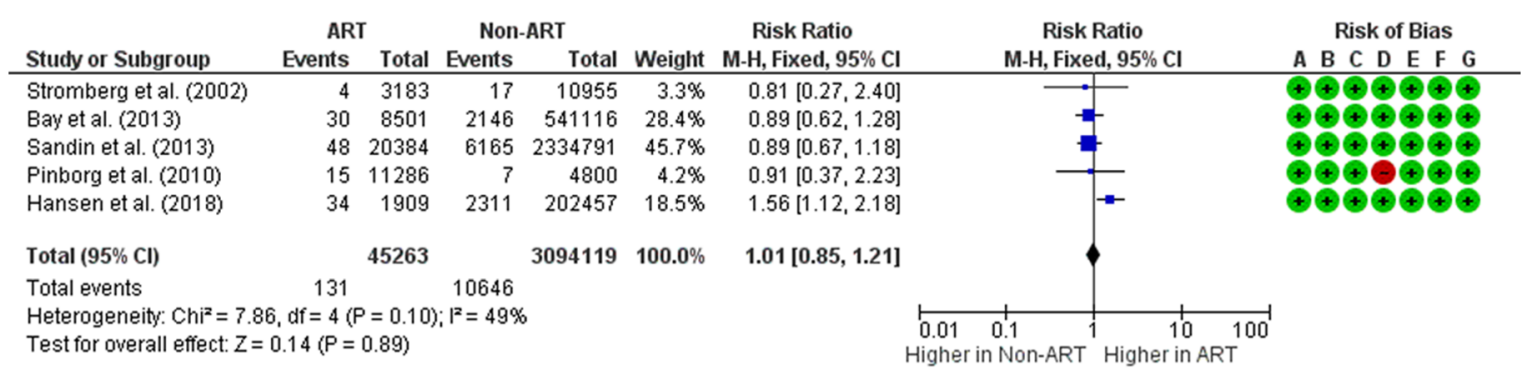

\section{Autism Spectrum Disorder}

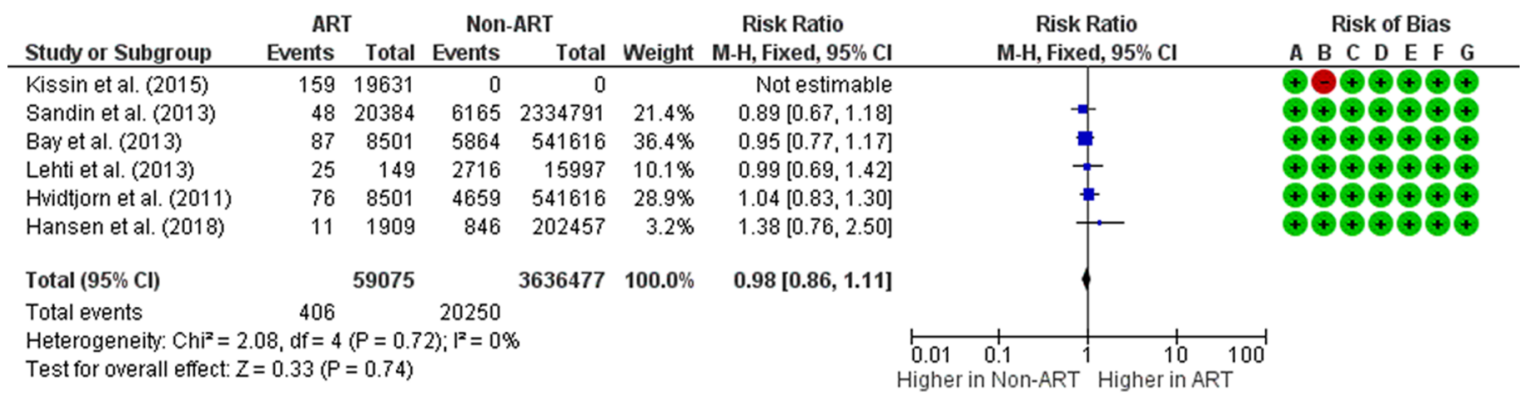

\section{Behavioral Problems}

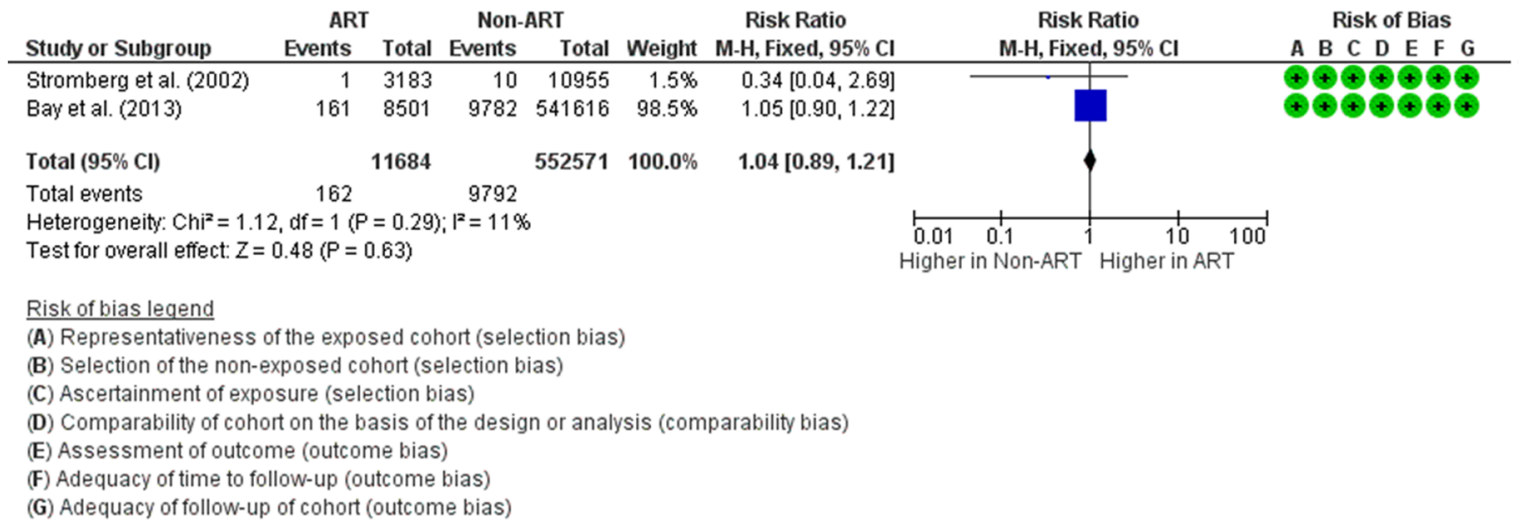

Fig. 2 Forest plot of neurodevelopmental disorders in children born from ART compared to children from natural conceptions. (a) Based on the reported prevalence of cerebral palsy in children from ART, it can be concluded that children born from ART have a higher risk of acquiring cerebral palsy compared to children from non-ART (natural conceptions). On the other hand, the risk of acquiring intellectual disability (b), autism spectrum disorder $(\mathbf{c})$, and behavioral problems (d) in children from ART is similar with children from natural conceptions 


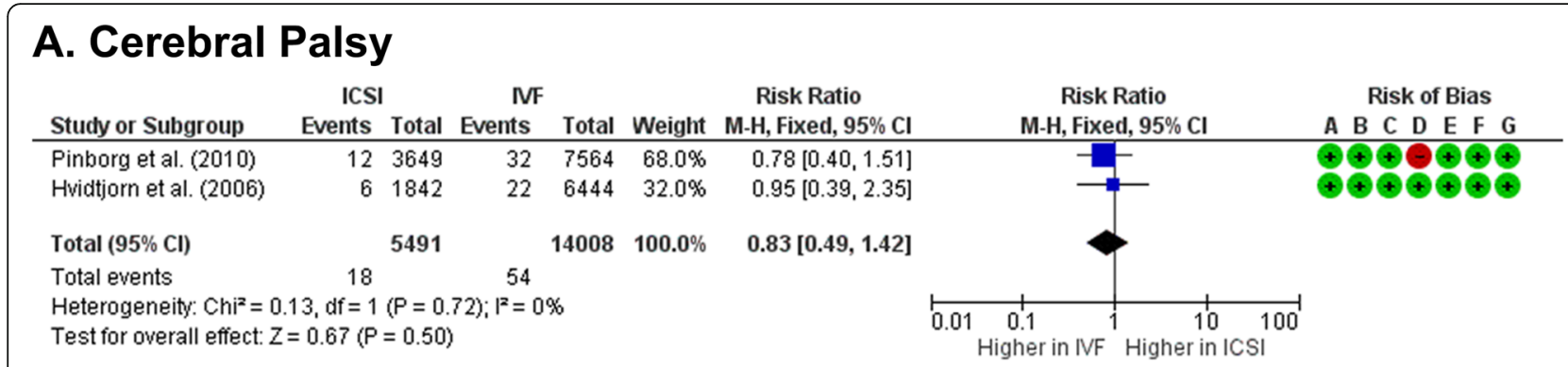

\section{B. Intellectual Disability}

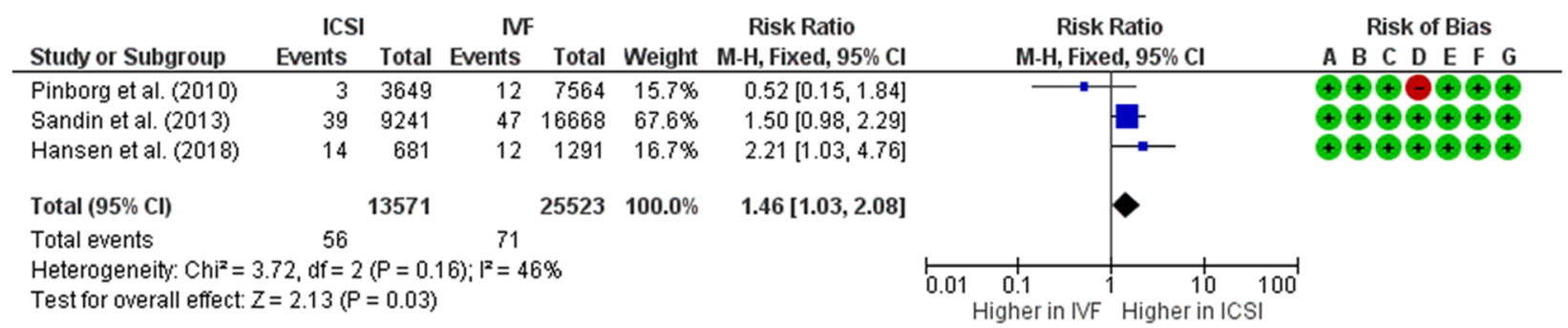

\section{Autism Spectrum Disorder}

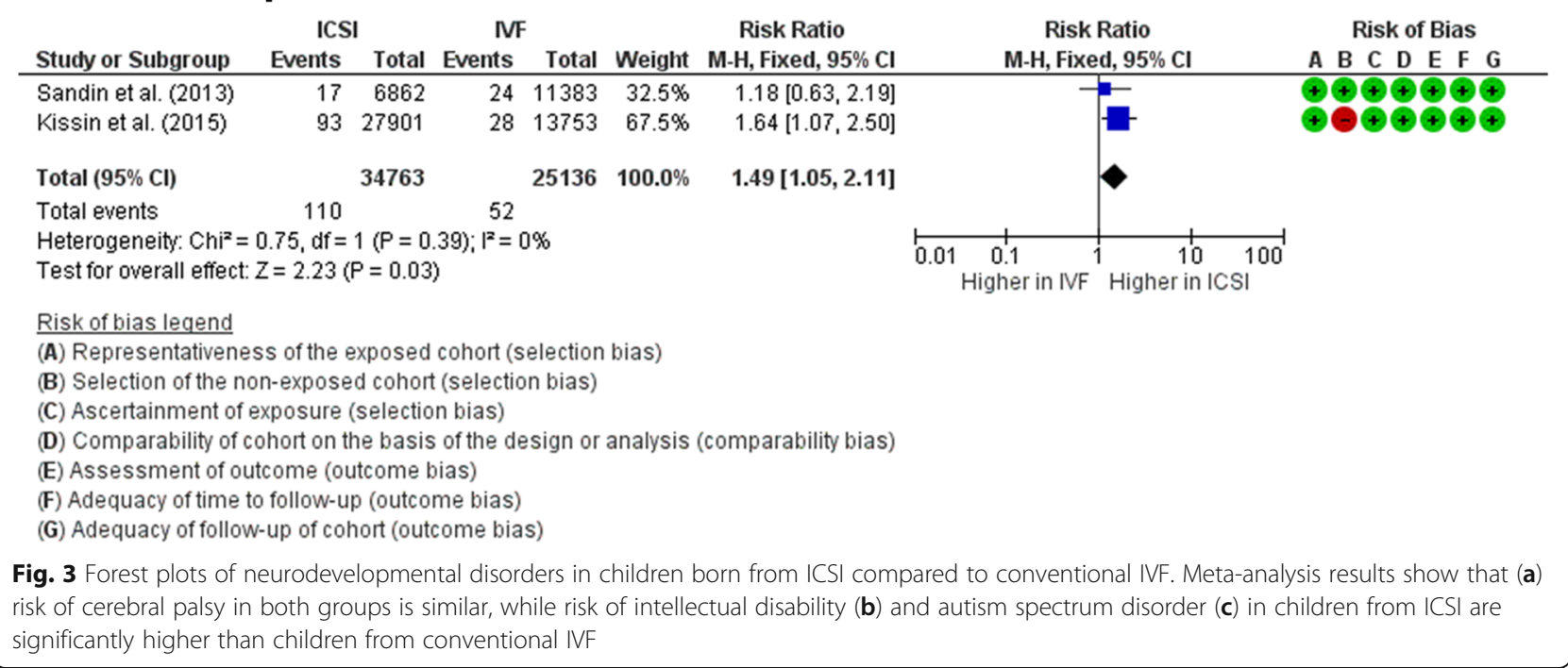

was due to one study of case-control with 1:2 ratio of children with CP and normal children [27]. Risk of publication bias (Egger's $p=0.974$ ) and small-study bias (Habord's $p=0.601$, Peter's $p=0.186$ ) were undetected (Supplemental Table 4).

\section{Risk of intellectual disability}

Prevalence of intellectual disability was reported in 3 studies [21, 26, 28]. Risk of intellectual disability in children born after frozen embryo transfer is not significantly different compared to children from fresh embryo transfer (RR 0.88 [0.63,1.22]; $z=0.78, p=0.44 ; I^{2}=0 \%, p=0.91$ ) (Fig. 4b), with absolute risk at 4 per 1000 births in frozen embryo transfer group and 5 per 1000 births in fresh embryo transfer group (Supplemental Table 7). Risk of publication bias (Egger's $p=0.619$ ) and small-study bias (Habord's $p=0.937$, Peter's $p=0.293$ ) were undetected (Supplemental Table 4).

\section{Risk of autism spectrum disorder}

Risk of ASD was reported in 2 studies [24, 28]. Risk of ASD in children born after frozen embryo transfer is similar to children from fresh embryo transfer (RR 0.81 [0.63, 1.05], $z=1.57, p=0.12 ; I^{2}=0 \%, p=0.76$ ) (Fig. 4c), with absolute risk at 7 per 1000 births in frozen group and 8 per 1000 birth in fresh group (Supplemental Table 7). The risk of bias statistic and small-study effects could 


\begin{tabular}{|c|c|c|c|c|c|c|c|c|}
\hline \multirow[b]{2}{*}{ Study or Subgroup } & \multicolumn{2}{|c|}{ Frozen } & \multicolumn{2}{|c|}{ Fresh } & \multirow[b]{2}{*}{ Weight } & \multirow{2}{*}{$\begin{array}{c}\text { Risk Ratio } \\
\text { M-H, Fixed, } 95 \% \mathrm{Cl}\end{array}$} & \multirow{2}{*}{$\begin{array}{c}\text { Risk Ratio } \\
\text { M-H, Fixed, } 95 \% \mathrm{Cl}\end{array}$} & Risk of Bias \\
\hline & Events & Total & Events & Total & & & & \multirow{4}{*}{ 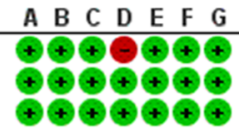 } \\
\hline Pinborg et al. (2010) & 2 & 884 & 42 & 10392 & $33.2 \%$ & $0.56[0.14,2.31]$ & \multirow{3}{*}{\begin{tabular}{l|l}
+2 \\
2
\end{tabular}} & \\
\hline Reid et al. $(2010)$ & 5 & 16 & 1236 & 3707 & $53.6 \%$ & $0.94[0.45,1.94]$ & & \\
\hline Hvidtjorn et al. (2006) & 3 & 343 & 22 & 5454 & $13.1 \%$ & $2.17[0.65,7.21]$ & & \\
\hline Total $(95 \% \mathrm{Cl})$ & & 1243 & & 19553 & $100.0 \%$ & $0.97[0.55,1.73]$ & & \\
\hline Total events & 10 & & 1300 & & & & & \\
\hline $\begin{array}{l}\text { Heterogeneity: } \mathrm{Chi}^{2}= \\
\text { Test for overall effect: }\end{array}$ & $\begin{array}{l}2.30, d f=2 \\
Z=0.09(P\end{array}$ & $\begin{array}{l}(P=0.3 \\
=0.93)\end{array}$ & $32) ; 1^{2}=1$ & $13 \%$ & & & 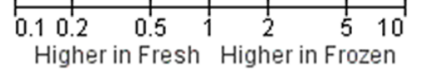 & \\
\hline B. Intellect & al Di & sabl & ility & & & & & \\
\hline & Froze & & Fres & & & Risk Ratio & Risk Ratio & Risk of Bias \\
\hline Study or Subgroup & Events & Total & Events & Total & Weight & M-H, Fixed, 95\% Cl & M-H, Fixed, $95 \% \mathrm{Cl}$ & A B C D E F G \\
\hline Sandin et al. (2013) & 21 & 4254 & 159 & 26537 & $58.2 \%$ & $0.82[0.52,1.30]$ & & $\oplus \oplus+\oplus \oplus \oplus \oplus$ \\
\hline Pinborg et al. (2010) & 1 & 884 & 14 & 10329 & $2.9 \%$ & $0.83[0.11,6.34]$ & & ๑૫)૫૯૯ \\
\hline Hansen et al. (2018) & 36 & 1757 & 24 & 1119 & $38.9 \%$ & $0.96[0.57,1.59]$ & & $\odot \odot \odot \odot \odot \odot \odot$ \\
\hline Total $(95 \% \mathrm{Cl})$ & & 6895 & & 37985 & $100.0 \%$ & $0.88[0.63,1.22]$ & & \\
\hline Total events & 58 & & 197 & & & & & \\
\hline $\begin{array}{l}\text { Heterogeneity: } \mathrm{Chi}^{2}= \\
\text { Test for overall effect: }\end{array}$ & $\begin{array}{l}0.18, d f=2 \\
Z=0.78(P\end{array}$ & $\begin{array}{l}(P=0 . \\
=0.44)\end{array}$ & 191); $\left.\right|^{2}=$ & & & & 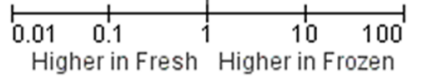 & \\
\hline C. Autism S & ectr & um & Disc & orde & & & & \\
\hline & Frozen & & Fres & & & Risk Ratio & Risk Ratio & Risk of Bias \\
\hline Study or Subgroup & Events & Total & Events & Total & Weight & M-H, Fixed, 95\% Cl & M-H, Fixed, 95\% Cl & A B C D E F G \\
\hline Sandin et al. (2013) & 11 & 4254 & 92 & 26537 & $18.2 \%$ & $0.75[0.40,1.39]$ & $\rightarrow$ & 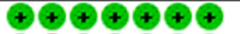 \\
\hline Kissin et al. (2015) & 56 & 6372 & 381 & 35996 & $81.8 \%$ & $0.83[0.63,1.10]$ & & $\odot \ominus \oplus \odot \oplus \oplus \odot$ \\
\hline Total $(95 \% \mathrm{Cl})$ & & 10626 & & 62533 & $100.0 \%$ & $0.81[0.63,1.05]$ & 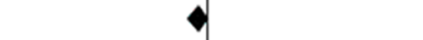 & \\
\hline Total events & 67 & & 473 & & & & & \\
\hline $\begin{array}{l}\text { Heterogeneity: } \mathrm{Chi}^{2}= \\
\text { Test for overall effect: }\end{array}$ & $\begin{array}{l}0.09, d f=1 \\
z=1.57(P\end{array}$ & $\begin{array}{l}(P=0 . \\
=0.12)\end{array}$ & $76) ; 1^{2}=0$ & & & & 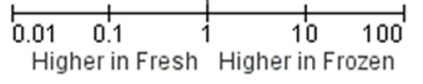 & \\
\hline Risk of bias legend & & & & & & & & \\
\hline (A) Representativene & s of the ex & posed & cohort (s & selection & bias) & & & \\
\hline (B) Selection of the no & n-exposed & cohort & t (selectio & n bias) & & & & \\
\hline (C) Ascertainment of $\mathrm{e}$ & xposure (s & election & (n bias) & & & & & \\
\hline (D) Comparability of $\mathrm{c}$ & hort on the & e basis & of the de & esign or & analysis ( & (comparability bias) & & \\
\hline (E) Assessment of ou & come (outc & come bi & & & & & & \\
\hline (F) Adequacy of time to & follow-up & (outcon & me bias) & & & & & \\
\hline (G) Adequacy of follow & up of coho & ort (outc & come bias & & & & & \\
\hline $\begin{array}{l}\text { Fig. } 4 \text { Forest plots of } n \\
\text { from meta-analysis of } p \\
\text { born from fresh embry }\end{array}$ & $\begin{array}{l}\text { eurodevelc } \\
\text { ublished d } \\
\text { transfer i }\end{array}$ & $\begin{array}{l}\text { opment } \\
\text { data on } \\
\text { n acqui }\end{array}$ & $\begin{array}{l}\text { tal disorc } \\
\text { neurode } \\
\text { iiring cer }\end{array}$ & $\begin{array}{l}\text { ders in c } \\
\text { evelopm } \\
\text { ebral pa }\end{array}$ & $\begin{array}{l}\text { children b } \\
\text { nental dis } \\
\text { alsy (a), in }\end{array}$ & $\begin{array}{l}\text { Dorn from frozen em } \\
\text { orders in children frc } \\
\text { tellectual disability ( }\end{array}$ & $\begin{array}{l}\text { nbryo transfer compared to fresh emb } \\
\text { rom frozen embryo transfer have simil } \\
\text { (b), and autism spectrum disorder }\end{array}$ & $\begin{array}{l}\text { oryo transfer. Results } \\
\text { lar risks with children } \\
\text { at later stages of life }\end{array}$ \\
\hline
\end{tabular}

not be estimated due to the limited number of studies (Supplemental Table 4).

Overall analysis showed that the children from frozen embryo transfer do not develop higher risk of neurodevelopmental disorders compared to children from fresh embryo transfer (RR 0.85 [0.70,1.03]; $z=1.69, p=0.09$; $\left.I^{2}=0 \%, p=0.87\right)$. The risk of neurodevelopmental disorder in children from frozen embryos is at 14 per 1000 births while in fresh embryos was 16 per 1000 births (Supplemental Table 7).

\section{Cofounder effects}

Additionally, potential cofounders to the results were also evaluated. Two cofounders' effects were confirmed by meta-analysis, including preterm birth and low birth body weight. The results showed that the risk of neurodevelopmental disorders is higher in children with history of preterm birth (RR 2.22 [2.15, 2.30]; $z=48.54, p<0.0001 ; I^{2}=$ $98 \%, p<0.0001$ ) (Fig. 5a), with the absolute risk is 6 more children born with neurodevelopmental disorders in every 1000 births (Supplemental Table 8). 


\section{A. Preterm Birth}

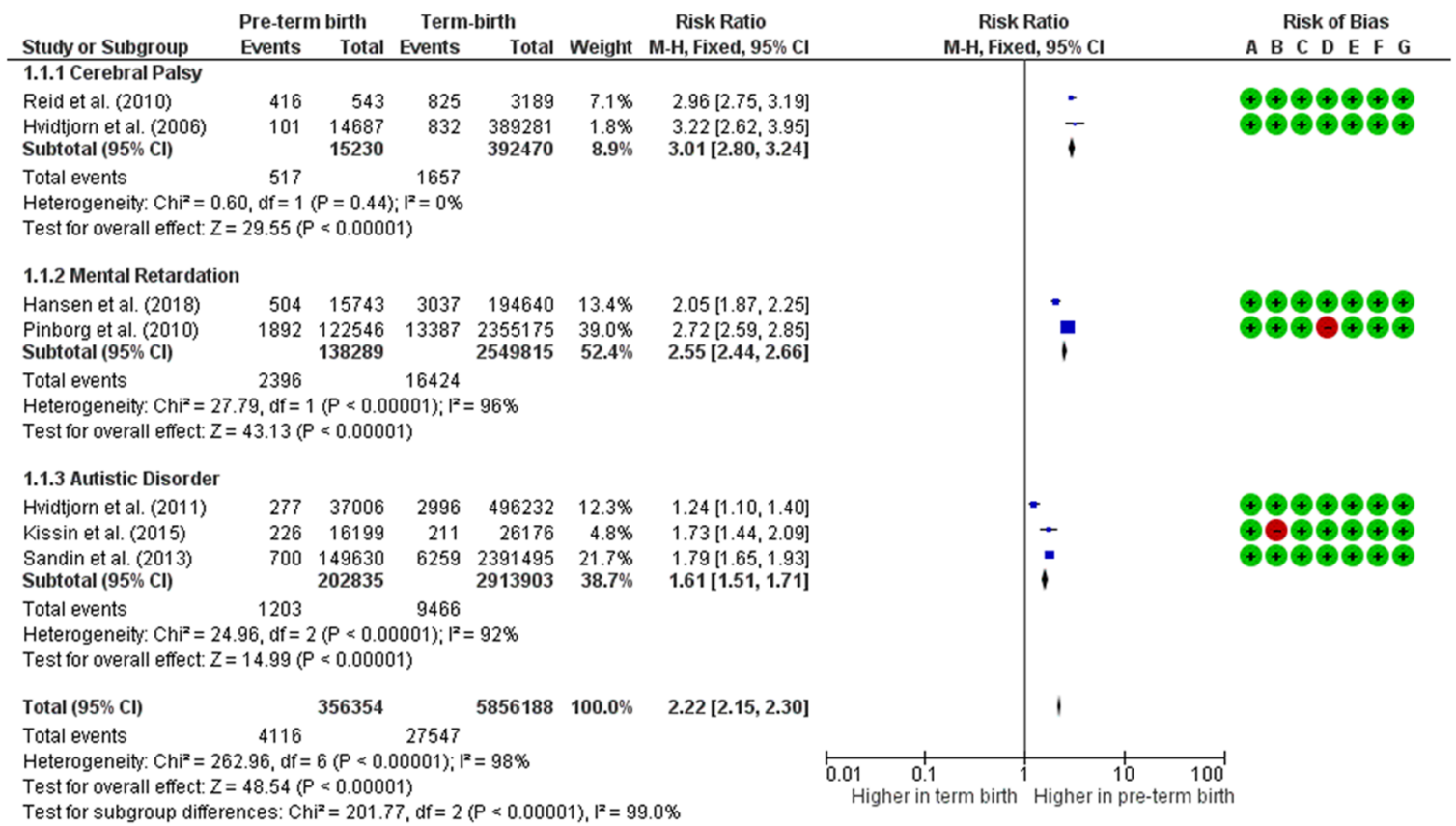

\section{B. Low Birth Weight}

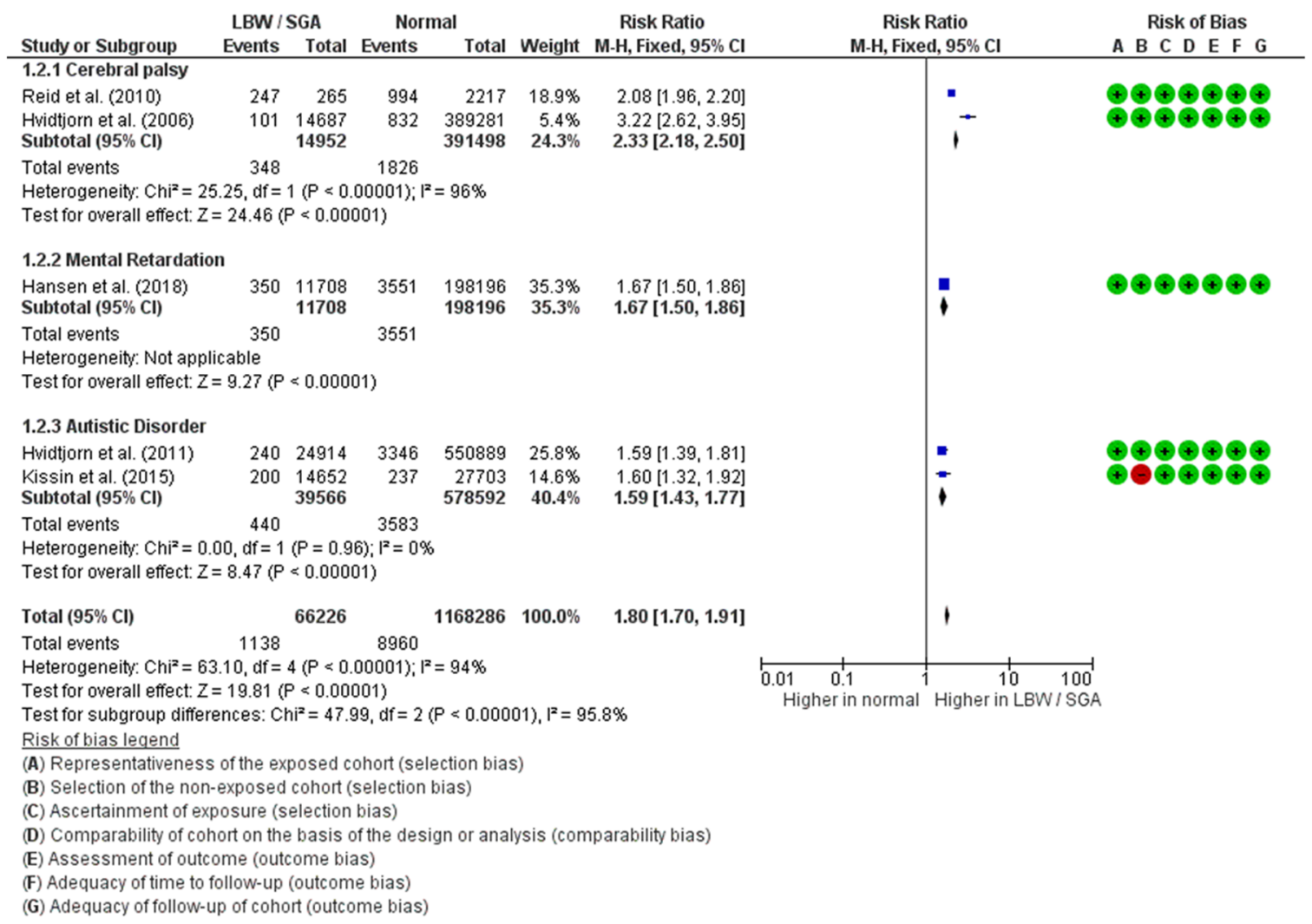

Fig. 5 Forest plots of potential cofounders in children from ART. The results of meta-analyses clearly show that children with history of preterm birth (a) or low birth body weight (b) would also have increased risks of acquiring neurodevelopmental disorders, including cerebral palsy, intellectual disability, and autistic disorders 
Meanwhile, the risk of neurodevelopmental disorders in children with history of low birth body weight (small for gestational age) is also higher compared to children without any history of low birth body weight (RR 1.80 [1.70 to 1.91 ]; $z=19.81, p<0.0001 ; I^{2}=$ 94\%, $p<0.0001$ ) (Fig. 5b), with the absolute risk is 6 more children born with neurodevelopmental disorders in every 1000 births (Supplemental Table 8).

ART procedures have the potentials to cause higher rates of multiple birth (RR 14.57 [14.42, 14.73], $z=$ 472.11, $\left.p<0.0001 ; I^{2}=100 \%, p<0.0001\right)$, preterm birth (RR 3.83 [3.82, 3.93], $z=472.11, p<0.0001 ; I^{2}$ $=100 \%, p<0.0001)$, and low birth body weight (RR 5.66 [5.50, 5.82], $z=118.10, p<0.0001 ; I^{2}=100 \%, p$ $<0.0001$ ) compared to non-ART procedure (Supplemental Figure 1), with the absolute risk of 386 more multiple birth, 167 more preterm birth, and 219 more low birth body weight per 1000 births (Supplemental Table 9).

\section{Discussion}

To our knowledge, a meta-analysis on the neurodevelopmental outcomes in children from ART has never been performed. This study aimed to make consensual conclusions from all studies that investigated the neurodevelopmental outcomes in children from ART, including ICSI, conventional IVF, frozen embryo transfer, and fresh embryo transfer. The results of this study are expected to provide the reliable information for the patients and healthcare workers to consider before starting ART.

As seen in Fig. 2, without taking specific details of the ART treatments into account, the results show that ART children develop an increased risk of cerebral palsy, but not intellectual disability, ASD, or behavioral problems. Cerebral palsy is a permanent neurological disorder characterized with disability to coordinate muscle tones and movements. This condition is caused by the damage or dysgenesis of brain part(s) that are involved in the coordination and movements of the body. It has been consensually accepted that the common risk factors for cerebral palsy are preterm birth and low birth body weight [31, 32]. In our study, we could confirm that these are the most likely risk factors that were presented among children from ART with cerebral palsy (Fig. 5, Supplemental Figure 1). The ART procedures are associated with higher preterm birth and low birth body weight, as they are also related to higher rates of multiple birth. ART procedures could cause monozygotic twinning related to zona pellucida manipulation and extended in vitro culture. Moreover, double embryo transfers during IVF procedures resulted in higher chance of multiple pregnancy [33]. Since the pathogenesis of cerebral palsy could be initiated with insults during gestation or after delivery, we could not conclude if the pathogenesis of cerebral palsy among ART children is due to the respiratory distress that is caused by immature lungs, which eventually lead to cerebral hypoxia after birth, or as a consequence of dysgenesis of part(s) of the brain that is related to movements and coordination. Nonetheless, these findings revealed the importance of optimum prenatal and neonatal care for ART children.

Interestingly, when the neurodevelopmental outcomes in children from ICSI were compared to the outcomes in children from conventional IVF, increased risks of intellectual disability and ASD were identified in the ICSI group. It is widely known that in some cases, intellectual disability and cerebral palsy are overlapping clinical conditions [34]. However, as the differences in the prevalence of cerebral palsy in children from ICSI and conventional IVF are statistically insignificant, we speculate that in these cases, intellectual disability is more likely due to inert factor(s), such as genetics. Furthermore, ASD has been associated with numerous genetic disorders, and has never been indicated as a result of neonatal insults. Thus, we argue that the cause of higher risks of intellectual disability and ASD in children from ICSI is genetic related.

As we know, ICSI is intended to prevent fertilization failure. One of the indications that becomes practitioners' common consideration when suggesting ICSI is sperm immotility [35]. Despite successes of achieving pregnancies after ICSI using immotile or morphologically abnormal spermatozoa [36-39], reports have suggested that the rates of DNA fragmentation in immotile spermatozoa are higher than in normal spermatozoa [40]. Furthermore, poor-quality oocytes, advanced maternal age, and unexplained infertility have also been used as indications to perform ICSI [41]. Each of the previously mentioned indication has also been associated with higher rates of DNA fragmentation; hence, this might be related to neurodevelopmental disorders. Study by Porokhovnik et al. correlates infantile autism with elevated DNA damage degree [41]; thus, our findings might be related to any of these factors.

As cryopreservation became more integrated to the common ART practice nowadays, the comparison between children from frozen embryo transfer with children from fresh embryo transfer was also performed. As previous reports have suggested, the risk of acquiring DNA fragmentations during cryopreservation and thawing processes might be associated with reduced numbers and proportion of trophectoderm cells [42], higher prevalence of neurodevelopmental disorders in children from frozen embryo transfer is expected. To our surprise, the meta-analysis results 
showed that there are no significant differences between the risks of neurodevelopmental disorders in children from frozen embryo transfer compared to the risk in children from fresh embryo transfer. Previous studies also reported that frozen embryo transfer resulted in increased live birth rate and higher neonatal birth body weight [43-45]. The improvement of cryopreservation techniques, such as vitrification and elective frozen embryo transfer, might result in better pregnancy and neonatal outcome [42, 46].

\section{Limitations}

The present study has several limitations. First, the number of studies that reported neurodevelopmental outcomes from different ART procedures is limited. This limitation correlates with the limited number of patients and the possibilities that some of the findings might be population specific. Secondly, singleton and multiple births could not be differentiated in some studies. Previous studies suggested that multiple pregnancy carries higher risks of prematurity and low birth body weight $[47,48]$, both could potentially contribute to the risks of neurodevelopmental disorders $[49,50]$. Third, the matched case-control studies could introduce potential conclusion bias on the absolute number of children at risk in the normal population. To overcome all of these limitations, future studies that involve larger populations with sufficient background information are required.

\section{Conclusion}

In conclusion, children from ART have a higher risk of acquiring cerebral palsy than children from natural conceptions. This increased risk is possibly associated with confounding factors, including preterm birth and low body birth weight. Based on this finding, it is reasonable to perform deliveries of children from ART at facilities with available neonatal intensive care unit (NICU); thus, treatment of potential cerebral insults after birth can be optimized. Furthermore, children from ICSI carry higher risks of intellectual disability and ASD than children from conventional IVF. These findings suggest the importance of long-term follow-up and preimplantation genetic screening, particularly in fertilizations by ICSI. Lastly, cryopreservation and thawing of embryos did not seem to cause increases in any risks of neurodevelopmental disorders; therefore, freeze-all strategy seemed plausible.

\section{Supplementary Information}

The online version contains supplementary material available at https://doi. org/10.1186/s11689-020-09347-w.

Supplemental Table 1. Newcastle Ottawa Scale on Cohort Studies. Supplemental Table 2. Newcastle-Ottawa Scale on Case-Control Studies.
Supplemental Table 3. Characteristics of the study. Supplemental Table 4. Statistical Summary of Meta-Analysis. Supplemental Table 5. Summary of findings and study quality assessment with GRADE approach of ART vs Non-ART studies. Supplemental Table 6. Summary of findings and study quality assessment with GRADE approach of ICSI vs IVF studies. Supplemental Table 7. Summary of findings and study quality assessment with GRADE approach of Frozen vs Fresh Embryo Transfer studies. Supplemental Table 8. Summary of findings and study quality assessment with GRADE approach of Confounder Effects studies. Supplemental Table 9. Summary of findings and study quality assessment with GRADE approach of Risk of Multiple Birth, Preterm Birth, Low birth body weight in ART and Non-ART children.

\section{Abbreviations}

ART: Assisted reproductive treatment; CP: Cerebral palsy; IVF: In vitro fertilization; ICSI: Intracytoplasmic sperm injection; LBW: Low birth body weight; PT: Preterm birth; SGA: Small for gestational age

\section{Acknowledgements}

Not applicable.

\section{Authors' contributions}

TD, WP, THA and DH conceptualized and designed the study. TD, JKA and $\mathrm{DH}$ did the literature screening, assessed study eligibility, quality and analyzed the data. JKA and DH did the statistical analysis. TD, THA, and DH directed the discussion. TD, JKA, WP, THA and DH reviewed and revised the manuscript. All authors approved the final manuscript as submitted and agreed to be accountable for all aspects of the work.

\section{Funding}

Not applicable.

Availability of data and materials

All data generated or analyzed during this study are included in this published article and its supplementary information files.

Ethics approval and consent to participate Not applicable.

\section{Consent for publication}

Not applicable.

\section{Competing interests}

Not applicable.

\section{Author details}

'Department of Obstetrics and Gynecology, Faculty of Medicine, Universitas Padjadjaran/Dr. Hasan Sadikin General Hospital, Bandung, West Java, Indonesia. ${ }^{2}$ Bandung Fertility Center, Limijati Mother and Child Hospital, Bandung, West Java, Indonesia. ${ }^{3}$ Department of Basic Medical Science, Faculty of Medicine, Universitas Padjadjaran, Bandung, West Java, Indonesia. ${ }^{4}$ Research Center for Medical Genetics, Faculty of Medicine, Universitas Padjadjaran, Bandung, West Java, Indonesia.

Received: 2 September 2020 Accepted: 18 November 2020

Published online: 13 December 2020

\section{References}

1. Barnhart KT. Assisted reproductive technologies and perinatal morbidity: interrogating the association. Fertil Steril. 2013;99(2):299-302. https://doi.org/ 10.1016/j.fertnstert.2012.12.032.

2. Palermo GD, O'Neill CL, Chow S, Cheung S, Parrella A, Pereira N, Rosenwaks Z. Intracytoplasmic sperm injection: state of the art in humans. Reproduction. 2017;154(6):F93-F110. https://doi.org/10.1530/REP-17-0374.

3. Wong KM, Mastenbroek S, Repping S. Cryopreservation of human embryos and its contribution to in vitro fertilization success rates. FertilSteril. 2014; 102(1):19-26. https://doi.org/10.1016/j.fertnstert.2014.05.027.

4. Alviggi C, Conforti A, Carbone IF, Borrelli R, de Placido G, Guerriero S. Influence of cryopreservation on perinatal outcome after blastocyst- vs 
cleavage-stage embryo transfer: systematic review and meta-analysis. Ultrasound obstetgynecol. 2018;51:54-63. https://doi.org/10.1002/uog.18942.

5. Pelkonen S, Al H, Ritvanen A, Koivunen R, Martikainen H, Gissler M, et al. Major congenital anomaies in children born after frozen embryo transfer: a cohort study 1995-2006. Hum Rep. 2014;29(7):1552-7. https://doi.org/10. 1093/humrep/deu088.

6. Bardis N, Maruthini D, Balen AH. Modes of conception and multiple pregnancy: a national survey of babies born during one week in 2003 in the United Kingdom. Fertil Steril. 2005;84(6):1727-32. https://doi.org/10. 1016/j.fertnstert.2005.05.052.

7. Dar S, Lazer T, Shah PS, Librach CL. Neonatal outcomes among singleton births after blastocyst versus cleavage stage embryo transfer: a systematic review and meta-analysis. Hum Rep Upd. 2014;20(3):439-48. https://doi.org/ 10.1093/humupd/dmu001.

8. Finnstrom O, Kallen B, Lindam A, Nilsson E, Nygren KG, Olausson PO. Maternal and child outcome after in vitro fertilization- a review of 25 years of population-based data from Sweden. Acta Obstet Gynecol Scand. 2011; 90:494-500. https://doi.org/10.1111/j.1600-0412.2011.01088.x.

9. Klemetti R, Gissler M, Sevon T, Koivurova S, Ritvanen A, Hemminki E. Children born after assisted fertilization have an increased rate of major congenital anomalies. Fertil Steril. 2005;84(5):1300-7. https://doi.org/10.1016/ j.fertnstert.2005.03.085.

10. Henningsen AKA, Bergh C, Skjaerven R, Tiitinen A, Wennerholm UB, Romundstad LB, et al. Trends over time in congenital malformations in liveborn children conceived after assisted reproductive technology. Acta Obstet Gynecol Scand. 2018;97:816-23. https://doi.org/10.1111/aogs.13347.

11. Liberati A, Altman DG, Tetzlaff J, Mulrow C, Gotzsche PC, loannidis JP, Clarke M, Devereaux PJ, Kleijnen J, Moher D. The PRISMA statement for reporting systematic reviews and meta-analyses of studies that evaluate healthcare interventions: explanation and elaboration. BMJ. 2009;339:b2700.

12. Wells GA, Shea B, O'Connell D, Peterson J, Welch V, Losos M, Tugwell P. The Newcastle-Ottawa Scale (NOS) for assessing the quality of nonrandomised studies in meta-analyses. http://www.ohri.ca/programs/clinical_ epidemiology/oxford.asp 2014

13. Belva F, Henriet S, Liebaers I, Van Steriteghem A, Celestin-Westreich S, Bonduelle M. Medical outcome of 8-year-old singleton ICSI children (born $>32$ weeks' gestation) and a naturally conceived comparison group. Hum Rep. 2007;22(2):506-15. https://doi.org/10.1093/humrep/del1372.

14. Beydoun HA, Sicignano N, Bedoun MA, Matson DO, Bocca S, Stadtmuer L, Oehninger S. A cross-sectional evaluation of the first cohort of young adults conceived by in vitro fertilization in the United States-sectional evaluation of the first cohort of young adults conceived by in vitro fertilization in the United States. Fertil Steril. 2010;94(6):2043-9. https://doi.org/10.1016/j. fertnstert.2009.12.023.

15. D'Souza SWD, Rivlin E, Cadman J, Richards B, Buck P, Lieberman BA Children conceived by in vitro fertilization after fresh embryo transfer. Arch Dis Child. 1997;76:F70-4.

16. Knoester M, Helmerhorts FM, Venbroucke JP, van der Westerlaken LJ, Walther FJ, Veen S, et al. Cognitive development of singletons born after intracytoplasmic sperm injection compared with in vitro fertilization natural conception. Fertil Steril. 2008;90(2):289-6. https://doi.org/10.1016/j.fertnstert. 2007.06.090

17. Middelburg KJ, Heineman MJ, Bos AF, Pereboom M, Fidler V, Hadders-Algra M. The Groningen ART cohort study: ovarian hyperstimulation and the in vitro procedure do not affect neurological outcome in infancy. Hum Rep. 2009;24(12):3119-26. https://doi.org/10.1093/humrep/dep310.

18. Pinborg A, Loft A, Schmidt L, Andersen AN. Morbidity in a Danish National cohort of 472 IVF/ICSI twins, 1132 non-IVF/ICSI twins, and 634 IVF/ICSI singletons: health-related and social implications for the children and their families. Hum Rep. 2003;18(6):1234-43. https://doi.org/10.1093/humrep/deg257.

19. Pinborg A, Loft A, Schmidt L, Greisen G, Rasmussen S, Andersen AN. Neurological sequelae in twins born after assisted conception: controlled national cohort study. BMJ. 2004. https://doi.org/10.1136/bmj. 38156.715694.3A.

20. Bay B, Mortensen EL, Hvidtjorn D, Kesmonel US. Fertility treatment and risk of childhood and adolescent mental disorders: register based cohort study. BMJ. 2013;347:f3978. https://doi.org/10.1136/bmj.f3978.

21. Hansen M, Greenop KR, Bourke J, Baynam G, Hart RJ, Leonard H. Intellectual disability in children conceived using assisted reproductive technology. Paediatrics. 2018;142(6):e20181269. https://doi.org/10.1542/ peds.2018-1269.
22. Hvidtjorn D, Grove J, Schendel DE, Vaeth M, Ernst E, Nielsen LF, Thorsen P. Cerebral palsy among children born after in vitro fertilization: the role of preterm delivery - a population-based, cohort study. Paediatrics. 2006; 118(2):475-84. https://doi.org/10.1542/peds.2005-2582

23. Hvidtjorn D, Grove J, Schendel D, Schieve LA, Svaerke C, Ernst E, Thorsen P. Risk of autism spectrum disorder in children born after assisted conception: a population-based follow-up study. J Epidemiol Commun H. 2011;65:497502. https://doi.org/10.1136/jech.2009.093823.

24. Kissin DM, Zhang Y, Boulet SL, Fountain C, Bearman P, Schieve L, YearginAllsopp $M$, Jamieson DJ. Association of assisted reproductive technology (ART) treatment and parental infertility diagnosis with autism spectrum disorder in ART-conceived children. Hum Rep. 2015;30(2):454-65. https://doi.org/10.1093/humrep/deu338.

25. Lehti V, Brown AS, Gissler M, Rihko M, Suominen A, Sourander A. Autism spectrum disorder in IVF children: a national case-control study in Finland. Hum Rep. 2013;28(3):812-8. https://doi.org/10.1093/humrep/ des430.

26. Pinborg A, Loft A, Henningsen AKA, Rasmussen S, Andersen AN. Infant outcome of 957 singletons born after frozen embryo replacement: The Danish National Cohort study 1995-2006. Fertil Steril. 2010;94(4):1320-7. https://doi.org/10.1016/j.fertnstert.2009.05.091.

27. Reid SM, Jaques AM, Susanto C, Breheny S, Reddihough DS, Halliday J. Cerebral palsy and assisted reproductive technologies: a case-control study. Dev Med Child Neurol. 2010;51:e161-6. https://doi.org/10.1111/j.1469-8749. 2009.03556.x.

28. Sandin S, Nygren KG, lliadou A, Hultman CM, Reichenberg A. Autism and intellectual disability among offspring born after in vitro fertilization. JAMA. 2013:310(1):75-84

29. Stromberg B, Dhalquist G, Ericson A, Finnstrom O, Knoster M, Stjernqvist K. Neurological sequelae in children born after in-vitro fertilization: a population-based study. Lancet. 2002;359:461-5.

30. Harris JC. New terminology for mental retardation in DSM-5 and ICD-11. Curr Opin Psychiatry. 2013;26(3):260-2.

31. Oskoui M, Coutinho F, Dykeman J, Jette N, Pringsheim T. An update on the prevalence of cerebral palsy: a systematic review and meta-analysis. Dev Med Child Neurol. 2013;55(6):509-19. https://doi.org/10.1111/dmcn. 12080.

32. Vincer MJ, Joseph KS, Allen AC, Stinson DA. Increasing prevalence of cerebral palsy among very preterm infants: a population-based study. Pediatrics. 2007;118(6):e1621-6. https://doi.org/10.1542/peds.2006-1522.

33. Broughton DE, Jungheim ES. 7-multiple gestations and assisted reproductive technology. Avery's Dis Newborn. 2018;10:70-77.e4. https://doi. org/10.1016/B978-0-323-40139-5.00007-3.

34. Jan MMS. Cerebral palsy: comprehensive review and update. Ann Saudi Med. 2006;26(2):123-32. https://doi.org/10.5144/0256-4947.2006.123.

35. Chen $H$, Feng $G$, Zhang B, Zhou H, Wang C, Shu J, et al. A new insight into male fertility preservation for patients with completely immotile spermatozoa. Reprod Boil Endocrinol. 2017;15(1):74. https://doi.org/10.1186/ s12958-017-0294-x.

36. Njis M, Vaderzwalmen P, Vandamme B, Segal-Bertin G, Lejeune B, Segal L, et al. Fertilizing ability of immotile spermatozoa after intracytoplasmic sperm injection. Hum Reprod. 1996;11(10):2180-5. https://doi.org/10.1093/ oxfordjournals.humrep.a019073.

37. Kahraman S, Tasdemir M, Tasdemir I, Vicdan K, Ozgur S, Polat G, et al. Pregnancies achieved with testicular and ejaculated spermatozoa in combination with intracytoplasmic sperm injectin in men with totally or initially immotile spermatozoa. Hum Reprod. 1996;11:1343-6. https://doi.org/10.1093/oxfordjournals.humrep.a019384

38. Stalf T, Sachez R, Kohn FM, Schalles U, Kleinstein J, Vinz V, et al. Pregnancy and birth after intracytoplasmic sperm injectin with spermatozoa from a patient with tail stump syndrome. Hum Reprod. 1995;10:2112-4. https://doi.org/10.1093/oxfordjournals.humrep.a136244.

39. Yang S, Gao L, Wang W, Ding J, Xu Y, Li H. Successful intracytoplasmic sperm injection with testicular spermatozoa from a man with multiple morphological abnormalities of the sperm flagella: a case report. J Assist Reprod Genet. 2018;35(2):247-50. https://doi.org/10.1007/s10815017-1057-5.

40. Atshan M, Kakavand K, Hosseini SH, Gilani MAS, Meybodi AM, Sabbaghian M. Evaluation of sperm DNA fragmentation and chromatin structure in infertile men with immotile short-tail sperm defect. Andrologia. 2020;52(1): e13445. https://doi.org/10.1111/and.13445. 
41. Porokhovnik LN, Kostyuk SV, Ershova ES, Stukalov SM, Veiko NN, Korovina NY, et al. The maternal effect in infantile autism: elevated DNA damage degree in patients and their mothers. Biochem Moscow 2016;10:322-6. https://doi.org/10.1134/S1990750816040041.

42. Inaba Y, Miyashita S, Somfai T, Geshi M, Matoba S, Dochi O, et al. Cryopreservation method affects DNA fragmentation in trophectoderm and the speed of re-expansion in bovine blastocyst. Cryobiology. 2016;72(2):8692. https://doi.org/10.1016/j.cryobio.2016.03.006.

43. Shi $Y$, Wei D, Liang $X$, Sun $Y$, Liu J, Cao $Y$, et al. Live birth after fresh embryo transfer vs elective embryo cryopreservation/frozen embryo transfer in women with polycystic ovary syndrome undergoing IVF (FreFro-PCOS): study protocol for a multicenter prospective, randomized controlled clinical trial. Trials. 2014;15:154. https://doi.org/10.1186/17456215-15-154.

44. Spijkers S, Lens JW, Schats R, Lambalk CB. Fresh and frozen-thawed embryo transfer compared to natural conception: differences in perinatal outcome. Gynecolobstet Invest. 2017;82(6):538-46. https://doi. org/10.1159/000468935.

45. Zhang J, Du M, Li Z, Wang L, Hu J, Zhao B, et al. Fresh versus frozen embryo transfer for full-term singleton birth: a retrospective cohort study. J Ovarian Res. 2018;11(1):59. https://doi.org/10.1186/s13048-018-04320-x.

46. Loutradi KE, Kolibianakis EM, Venetis CA, Papanikolaou EG, Pados G, Bontis I, et al. Cryopreservation of human embryos by vitrification or slow freezing: a systematic review and meta analysis. Fertil Steril. 2008;90(1):186-93. https://doi.org/10.1016/j.fertnstert.2007.06.010.

47. Ooki S. The effect of an increase in the rate of multiple births on low-birthweight and preterm deliveries during 1975-2008. J Epidemiol.2010; 20(6): 480-0. doi: https://doi.org/10.2188/jea.je2010022.

48. Fuchs F, Senat MV. Multiple gestations and preterm birth. Semin Fetal Neonatal Med. 2016;21(2):113-20. https://doi.org/10.1016/j.siny/2015.12.010.

49. Franz AP, Bolat GU, Bolat H, Matijasevich A, Santos IS, Silveira RC, et al. Attention-deficit/hyperactivity disorder and very preterm/very low birth weight: a meta-analysis. Pediatrics. 2018;141(1):e20171645. https://doi.org/10. 1542/peds.2017-1645.

50. Schieve LA, Tian LH, Rankin K, Kogan MD, Yeargin-Allsopp M, Visser S, Rosenberg D. Population impact of preterm birth and low birth weight on developmental disabilities in US children. Ann Epidemiol. 2016;26(4):267-74. https://doi.org/10.1016/j.annepidem.2016.02.012.

\section{Publisher's Note}

Springer Nature remains neutral with regard to jurisdictional claims in published maps and institutional affiliations.

Ready to submit your research? Choose BMC and benefit from:

- fast, convenient online submission

- thorough peer review by experienced researchers in your field

- rapid publication on acceptance

- support for research data, including large and complex data types

- gold Open Access which fosters wider collaboration and increased citations

- maximum visibility for your research: over $100 \mathrm{M}$ website views per year

At BMC, research is always in progress.

Learn more biomedcentral.com/submissions 